\title{
COVID-19: Medidas de protección en salud materna
}

\section{COVID-19: Protection measures in maternal health}

Correspondencia Victor Hugo Moquillaza Alcántara victor.moquillaza@upch.pe

Recibido: $15 / 04 / 2020$ Aprobado: 29/04/2020

Citar como: Damacén-Oblitas V, Castro-Gómez D, Rojas-Silva J, Rojas-Vega J, MoquillazaAlcántara V. COVID-19: Medidas de protección en salud materna. Acta Med Peru. 2020;37(2):245-8. doi: https://doi.org/10.35663/ amp. 2020.372 .938

\author{
Valery Damacén-Oblitas 1,a, Diayan Castro-Gómez ${ }^{1, a}$, Jessica Rojas-Silva ${ }^{1, a}$, \\ Jennifer Rojas-Vega ${ }^{1, a}$, Victor Moquillaza-Alcántaraª \\ 1 Centro Federado de Obstetricia, Universidad Nacional Mayor de San Marcos. Lima, Perú \\ 2 Facultad de Salud Pública y Administración, Universidad Peruana Cayetano Heredia. Lima, Perú. \\ Estudiante de obstetricia; ${ }^{\text {l }}$ licenciado en obstetricia
}

Sr. Editor,

La enfermedad por coronavirus 2019 (COVID-19) ha alcanzado la categoría de pandemia, generando que los países propongan medidas de protección en salud pública. El 5 de febrero de 2020 se registró el primer caso de un recién nacido con COVID-19 en el mundo ${ }^{[1]}$, con lo cual surgió la preocupación de cuáles deben ser los cuidados que deben prestarse en la atención de la gestante infectada y en cuánto puede afectar el transcurso normal del embarazo.

Los estudios que abordan la salud materna y COVID-19 reportan que las gestantes tienen una edad promedio de 32 años y una edad gestacional media de 39 semanas, presentan fiebre o dificultad respiratoria leve en el posparto ${ }^{[1-5]}$. Asimismo, los neonatos presentaron rinorrea y congestión nasal, sin alcanzar dificultad respiratoria o fiebre. Esta ausencia de signos o síntomas de gravedad pueden enmascarar la infección en las pacientes obstétricas, por lo cual se sugiere iniciar acciones de protección para evitar el contagio en las salas de atención materna ${ }^{[1-5]}$.

Ante esta coyuntura, diversas instituciones han formulado sugerencias bajo el esquema de guías prácticas, las cuales son independientes entre los países y llegan a presentar diferentes recomendaciones. Tener un consolidado de estas sugerencias podría favorecer el cuidado de la salud materna. Por ello, nos planteamos como objetivo determinar cuáles son las recomendaciones para la protección de la salud materna frente a la COVID-19.

Se realizó una búsqueda y revisión documental de aquellas guías elaboradas durante el presente año (2020) por a) sociedades de ginecología y obstetricia, b) colegios profesionales, y c) entidades gubernamentales o d) instituciones internacionales, que propongan recomendaciones para la protección del profesional de la salud y la paciente obstétrica. Algunas instituciones contaban con más de un documento publicado. Los documentos fueron revisados por todos los autores de forma independiente. Luego, se reunió toda la información en una sola base, donde se excluyeron documentos duplicados y aquellas que no brinden medidas preventivas en salud materna, a continuación se unificaron aquellas sugerencias que, a pesar de ser de distintas instituciones, expresen lo mismo. La información fue categorizada en recomendaciones dirigidas al profesional, a la atención prenatal, gestante y puérpera. La búsqueda culminó el 9 de abril de 2020, cuando se observó una saturación de información. Se pone a disposición el nombre de los documentos revisados y los accesos web correspondientes en el siguiente repositorio: https://doi.org/10.6084/m9.figshare.12142521.v1. 
Tabla 1. Medidas de protección en salud materna frente a la COVID-19

Profesional de salud

Brindar a los profesionales de atención de parto un equipo de protección personal (EPP) para la prevención de infección por microorganismos transmitidos por gotas, lo cual incluye: Bata resistente a líquidos, mascarilla, guantes y protección ocular. Asimismo, capacitarlos en cómo colocarse y retirarse el

$a, b, c, d, e, f, g$, I, m EPP.

No poner en peligro los servicios de salud sexual y reproductiva al referir a los profesionales de atención de parto como personal de emergencia.

Dotar al personal de desinfectantes de manos, termómetros y recomendar medidas higiénicas adecuadas (distribuir y/o colocar geles alcohólicos en las zonas que se considere, colocar toallas de papel desechable en los baños, garantizar que haya jabón en los dispensadores, entre otros).

Mantener, en lo posible, una distancia de un metro con otros compañeros, especialmente, si presentan tos, estornudos o signos visibles de malestar general.

En caso de presentar fiebre, tos y sensación de falta de aire, se recomienda no acudir a trabajar y, de ser necesario, contactar con los teléfonos de información y emergencias previstos.

Se debe cumplir una estricta higiene de manos y antebrazos antes y después del contacto con el paciente y de la retirada del equipo de protección individual.

\section{Atención prenatal}

Se recomiendan seis consultas prenatales presenciales. Durante el primer trimestre espaciar las atenciones en intervalos de cinco a seis semanas.

La programación de atenciones prenatales debe evitar la aglomeración de gestantes o puérperas en los servicios.

De ser posible, maximizar el uso de medios remotos para proporcionar sistemas de consulta remota (telesalud), cumpliendo así las medidas de distanciamiento social recomendadas.

Los servicios de maternidad deben proporcionar información clara a las usuarias sobre los cambios de las atenciones prenatales en sus páginas web, redes sociales o notas electrónicas.

Utilizar las citas a domicilio siempre y cuando la gestante o puérpera y todos los miembros del hogar garanticen no estar infectados.

En caso de confirmar infección por COVID-19, se debe realizar el monitoreo materno fetal estricto.

Las gestantes con enfermedades respiratorias son de máxima prioridad en la atención debido al riesgo de resultados adversos.

En caso de riesgo de parto prematuro e infección por COVID-19, los beneficios clínicos del corticosteroide antenatal podrían superar los riesgos de daño potencial para la madre. En esta situación, el equilibrio de beneficios y daños para la mujer y el recién nacido prematuro debe discutirse con la mujer para garantizar una decisión informada.

Continuar atención en consultorio de alto riesgo obstétrico, evitando el traslado de pacientes en transporte público, facilitando un móvil o vehículo. Asimismo, se debe evitar la exposición de esta población al virus.

\section{Gestante}

Mantener una distancia física con su entorno, además de evitar tocarse los ojos, nariz o boca.

Evitar el contacto con personas que presenten síntomas de resfrío.

Ser monitoreadas si presentan antecedentes epidemiológicos de contacto.

En caso de confirmar COVID-19, usar sus propias toallas, vajilla y utensilios, y comer en diferentes momentos.

Abstenerse de viajar innecesariamente, estar en multitudes o utilizar el transporte público. 
Tabla 1. Medidas de protección en salud materna frente a la COVID-19 (Viene de pág. anterior)

\section{Puérpera}

Las madres con sospecha o confirmación de COVID-19 deben utilizar mascarilla al amamantar, lavarse las manos antes y después del contacto con el neonato y desinfectar las superficies con las que la madre tuvo contacto.

$a, b, I$

b, c, f

debe alentar y apoyar en la extracción de leche.

Las madres con COVID-19 y una enfermedad grave que le impida la extracción, deben optar por otras alternativas que permitan sostener la alimentación con leche humana o con sustitutos apropiados de la leche materna.

Inmediato al nacimiento y durante la lactancia materna, ya sea que la madre o el recién nacido tenga sospecha o confirmación de COVID-19, se puede realizar el contacto piel a piel, el cuidado de la madre canguro cuando sea indicado y el alojamiento durante el día y la noche.

En madres asintomáticas con infección confirmada o probable y recién nacido asintomático se debe mantener alojamiento entre madre e hijo, con cuna separada a 2 metros de la cama de la madre.

Asimismo, valorar continuar en régimen de aislamiento domiciliario bajo seguimiento telefónico por un profesional sanitario cualificado.

Si una mujer con COVID-19 no se siente bien como para amamantar, debe recibir apoyo para proporcionarle leche materna de manera segura a su bebé de otras maneras: extracción de la leche, relactación, donante de leche humana.

Limitar las visitas a las instalaciones hospitalarias; en su defecto, que los visitantes sean examinados previamente.

Ante la ausencia de complicaciones posparto, se debe favorecer el alta temprana teniendo en cuenta todas las medidas de apoyo continuo.

Frente a la posible exacerbación de la ansiedad y depresión posnatal, se sugiere una consejería brindada por un especialista en maternidad. Se sugiere seguimiento por teléfono y/o vídeo.

Para los bebés alimentados con biberón, con fórmula o leche extraída, se recomienda el estricto cumplimiento de las pautas de esterilización.

Organización emisora de la recomendación: a. Organización Mundial de la Salud; b. Organización Panamericana de la Salud; c. Fondo de Población de las Naciones Unidas; d: Public Health England; e. Royal College of Midwife + Royal College of Obstetricians \& Gynaecologists; f. Sociedad Española de Ginecología y Obstetricia; g. Consejo General de la Psicología; h. Ministerio de Sanidad (España); i: Ministerio de Salud (Argentina); j. Ministerio de Salud (Colombia); k. Federación Colombiana de Obstetricia y Ginecología; I: Sociedad Peruana de Ginecología y Obstetricia; m. Colegio de Obstetras del Perú.

La búsqueda encontró recomendaciones brindadas por la Organización Mundial de la Salud, Organización Panamericana de la Salud, Fondo de Población de las Naciones Unidas (UNFPA), Public Health England (Reino Unido), Royal College of Midwife (Reino Unido), Royal College of Obstetricians \& Gynaecologists (Reino Unido), Sociedad Española de Ginecología y Obstetricia, Consejo General de la Psicología (España), Ministerio de Sanidad (España), Ministerio de Salud (Argentina), Ministerio de Salud (Colombia), Sociedad Colombiana de Obstetricia y Ginecología, Sociedad Peruana de Obstetricia y Ginecología y del Colegio de Obstetras del Perú (Tabla 1).

Los resultados mostraron que las recomendaciones brindadas hacia los profesionales de la salud están basadas en: a) la protección del individuo, sea este mediante elementos de barrera (bata, mascarilla, guantes y protección ocular) o desinfectantes (jabón, alcohol en gel, toallas desechables, entre otros), y en b) evitar su desplazamiento a otros servicios, a fin de que no se conviertan en los portadores del virus. Respecto a la atención prenatal, existe una tendencia a reducir el contacto entre personas, mediante la reducción al control prenatal mínimo (seis atenciones) como la programación adecuada de citas, considerando evitar aglomeraciones, y la asistencia remota.

Respecto a la paciente obstétrica, las recomendaciones se restringen al cuidado personal, evitando el contacto con personas como en el transporte público o manteniendo separadas sus pertenencias, y una higiene constante. Respecto a la puérpera, se ha referido el cuidado que debe mantenerse durante la lactancia, donde diversas guías manifiestan que esta debe mantenerse aún con sospecha o confirmación de COVID-19, realizándose siempre con la protección debida (mascarilla e higiene antes y después del contacto con el neonato). Durante el proceso no se hallaron discordancias entre las recomendaciones seleccionadas.

Un estudio realizado en febrero de 2020 realizado en Shangai, refiere que las gestantes presentan una preocupación crítica por el riesgo al contagio de infección por COVID-19, más aún si no conocen qué repercusiones puede presentar en su 
salud o la de su recién nacido; asimismo, están de acuerdo con la implementación de una serie de medidas, tales como incrementar el lapso entre atenciones prenatales y obtener información vía remota ${ }^{[6]}$. Es preciso indicar que en la búsqueda no se ha hallado otra evidencia en revistas científicas que aborde el cuidado del profesional en salud materna o la paciente obstétrica.

Finalmente, las recomendaciones descritas se circunscriben a los reportes disponibles, siendo mayormente guías que pueden actualizar su conocimiento constantemente. Sin embargo, consideramos que este consolidado de recomendaciones puede ser de utilidad para las próximas políticas que se empleen en campos específicos como la salud materna.

Contribuciones de autoría: VHMA ha participado en la concepción de la idea. Todos los autores participaron en el diseño de estudio, recolección de información, interpretación y discusión de los resultados, redacción del manuscrito y evaluación de la versión final.

Potenciales conflictos de interés: los autores declaran no tener conflictos de interés.

Fuente de financiamiento: autofinanciado.

\section{ORCID:}

Valery Damacén-Oblitas: https://orcid.org/0000-0002-8835-7543

Diayan Castro-Gómez: https://orcid.org/0000-0003-4054-3061
Jessica Rojas-Silva: https://orcid.org/0000-0002-0718-7272

Jennifer Rojas-Vega: https://orcid.org/0000-0002-3205-1633

Victor Moquillaza-Alcántara: https://orcid.org/0000-0002-0362-907X

\section{REFERENCIAS BIBLIOGRÁFICAS}

1. Zeng LK, Tao XW, Yuan WH, Wang J, Liu X, Liu ZS. First case of neonate with COVID-19 in China. Chinese Journal of Pediatrics. 2020;58(4):279280. doi: 10.3760/cma.j.cn112140-20200212-00081

2. Yu N, Li W, Kang Q, Xiong Z, Wang S, Lin X. Clinical features and obstetric and neonatal outcomes of pregnant patients with COVID-19 in Wuhan, China: a retrospective, single-centre, descriptive study. Lancet. 2020;\$1479-3099(20):30176. doi: 10.1016/S1473-3099(20)30176-6

3. Chen S, Liao E, Shao Y. Clinical analysis of pregnant women with 2019 novel coronavirus prneumonia. J Med Virol. 2020. doi: 10.1002/ jmv.25789

4. Li N, Han L, Peng M, Lu Y, Ouyang Y, Liu K, et al. Maternal and Neonatal outcomes of pregnant women with COVID-19 pneumonia: A case-control study. Clin Infect Dis. 2020. doi: 10.1093/cid/ciaa352

5. Zaigham M, Andersson O. Maternal and Perinatal Outcomes with COVID-19: a systematic review of 108 pregnancies. Acta Obstetricia et Gynecologica Scandinavica. 2020. doi: 10.1111/ aogs. 13867

6. Du L, Gu YB, Cui MQ, Li WX, Wang J, Zhu LP, Xu B. Investigation on demands for antenatal care services among 2002 pregnant women during the epidemic of COVID-19 in Shanghai. Zhonghua Fu Chan Ke Za Zhi. 2020;55(3):160-165. doi: 10.3760/ cma.j.cn112141-20200218-00112 